\title{
La Corte Interamericana de Derechos Humanos y un caso de monto indemnizatorio excesivo: Caso ex Magistrados Corte Suprema versus Ecuador.
}

\author{
The Inter-American Court of Human Rights \\ and an excessive compensation amount case: \\ Former Supreme Court Justices v. Ecuador
}

\author{
Prof. Dr. Hernán Salgado Pesantes*
}

Corte Constitucional del Ecuador

\section{Infomación del Artículo}

Original - Ruptura, 2020

Artículo recibido / Received: 3 de junio, 2020

Artículo aceptado / Accepted: 2 de julio, 2020

\section{Citación}

Salgado, H. (2020). La Corte Interamericana de Derechos Humanos y un caso de monto indemnizatorio excesivo: Caso ex Magistrados Corte Suprema versus Ecuador. Revista Ruptura de la Asociación Escuela de Derecho PUCE. Edición 2020, p (21-34).

* Abogado y Doctor en Jurisprudencia por la Universidad de Guayaquil (1967). Doctor en Ciencias Políticas PhD por la Universidad de Pantheón-Soborna de París. Profesor principal de Derecho Constitucional y de Introducción al Derecho en la Pontificia Universidad Católica del Ecuador (1978-2012). Decano de la Facultad de Jurisprudencia de la PUCE (1987-1989). Profesor invitado de la Universidad de París X- Nanterre (1990-2000). Juez de la Corte Interamericana de Derechos Humanos: 1er período: 1992-1997 y 2do período: 1998-2003. Electo presidente de la misma (1997-1999). Magistrado del Tribunal Constitucional del Ecuador (1999-2003). Magistrado de la Corte Suprema de Justicia del Ecuador (2005-2008). Miembro de la Asamblea General del Instituto Interamericano de Derechos Humanos y de los Institutos Iberoamericanos de Derecho Constitucional y Procesal Constitucional. Presidente de la Corte Constitucional de la República del Ecuador (desde 2019 hasta la fecha). 
DOI: $10.26807 /$ rr.vi02.57

Resumen: El presente artículo analiza la decisión de la Corte Interamericana de Derechos Humanos frente al emblemático caso sobre el cese de funciones de varios ex magistrados de la Corte Suprema de Justicia de Ecuador. Se declaró por parte del organismo internacional, responsabilidad internacional al Estado ecuatoriano por la vulneración de derechos reconocidos en la Convención Americana sobre Derechos Humanos. Estableciendo como medida de reparación, una indemnización excesiva como forma de sanción a Ecuador, mas no como una medida de reparación compensatoria para las víctimas y sus familiares. Factor que logra llamar la atención, pues la decisión tomada por la Corte Interamericana de Derechos Humanos se alejó de sus propios fallos.

Palabras clave: Indemnización, reparación, Ecuador, sanción, Corte Interamericana de Derechos Humanos, Ecuador

\begin{abstract}
This article analyses the decision taken by the Inter-American Court of Human Rights in the emblematic case of the dismissal of several former judges of the Supreme Court of Justice of Ecuador. The international organization declared the Ecuadorian State to be internationally responsible for the violation of rights recognized in the American Convention on Human Rights. It established excessive compensation as a form of punishment for Ecuador, but not as a measure of compensatory reparation for the victims and their families. This is a factor that draws attention to the fact that the decision taken by the Inter-American Court of Human Rights was far removed from its own judgments.
\end{abstract}

Keywords: Compensation, reparation, Ecuador, sanction, Inter-American Court of Human Rights. 


\section{Introducción}

Al analizar el Caso de los ex magistrados de la Corte Suprema del Ecuador la intención es, contribuir con un pequeño aporte a las reflexiones que la Corte Interamericana de Derechos Humanos desarrolla sobre la materia de reparaciones e indemnizaciones. Cuestiones que revisten cierta complejidad tratándose de una diversidad de situaciones que los juzgadores deben considerar.

Cuando ha sido violado uno -o más derechos- establecidos en la Convención Americana y la Corte establece la responsabilidad internacional del Estado Parte, éste debe reparar el daño ocasionado. En esta etapa procesal corresponde a la Corte Interamericana determinar cómo debe ser esa reparación y, entonces, el principio que guía es el de la reparación integral, que como su nombre lo indica busca reparar por diversos medios el derecho conculcado, no sólo a la víctima sino también a sus familiares.

El caso de los ex Magistrados de la Corte Suprema del Ecuador reviste aspectos de interés por diversos factores, que no son sólo jurídicos. Es importante, analizar cómo los jueces de la Corte Interamericana llegaron a establecer un monto indemnizatorio que, personalmente, considero excesivo.

Además, mi calidad de ecuatoriano me permite encontrar fácilmente las razones políticas que, en este caso, tuvo el Gobierno de la época. Lo que explica la inoperancia de la Procuraduría General del Estado encargada de defender al país. Asimismo, me permite observar las actuaciones vergonzosas de algunos ex magistrados que están reñidas con la ética y la moral.

En todo caso, lo que buscamos quienes estamos vinculados al Sistema Interamericano de Derechos Humanos, es encontrar un modelo de reparación indemnizatoria que sea equitativo frente a esa diversidad de situaciones, que sea razonablemente proporcional con el derecho o los derechos violados. 


\section{Reparaciones e Indemnizaciones}

Como señala la Corte IDH la "restitutio in integrum" se refiere a una de las formas de reparación de un acto ilícito internacional, pero no es la única medida de reparación. Pueden existir casos en que la "restitutio" no sea posible, suficiente o adecuada, por lo que resulta necesario aplicar otras formas de reparación en favor de la víctima y de sus familiares.

Una de las formas de reparación es la indemnización. El artículo 63 de la Convención Americana dispone "el pago de una justa indemnización”, la cual corresponde en primer término a los perjuicios sufridos por la víctima, y comprende tanto el daño material como el moral (o inmaterial). A esta forma de reparación la Corte la denominó indemnización compensatoria, desde los primeros casos contenciosos. Siguiendo el patrón del ius civile, el daño material involucra al lucro cesante y al daño emergente, cuestiones que exigen ser probadas en el proceso de reparaciones. Junto al daño material, se considera el daño inmaterial o comúnmente llamado daño moral, el mismo que será establecido en equidad ante la dificultad de encontrar parámetros de evaluación económica.

Sobre el daño moral la Corte Interamericana ha señalado que son muchos los casos en que otros tribunales internacionales han acordado que la sentencia de condena per se constituye una indemnización suficiente del daño moral (y cita jurisprudencia de la Corte Europea de los años 1990 a 1994). Sin embargo, la Corte reconoce que lo dicho no tiene cabida cuando se trata de graves violaciones del derecho a la vida, con ejecuciones extrajudiciales o desapariciones forzadas, o bien se atenta a la libertad e integridad personal con torturas crueles, entre otros casos, que son los que se presentan ante el Sistema Interamericano.

Y, es en tales situaciones que el sufrimiento moral causado a las víctimas y a su familia es intenso, lo que justifica la indemnización pecuniaria que habrá que fijarla "conforme a la equidad y basándose en una apreciación prudente del daño moral, el cual no es susceptible de una tasación precisa” (Corte IDH, Serie C, No. 43, 1998, párr. 84). 
Por último, cabe agregar que para las reparaciones e indemnizaciones es importante tener presente que cada caso debe analizarse dentro de sus especificidades, con base en la jurisprudencia. "(L)a jurisprudencia, dice la Corte, puede servir de orientación para establecer principios en esta materia, aunque no puede invocarse como criterio unívoco a seguir porque cada caso debe analizarse en sus especificidades" (Corte IDH, Serie C, No. 29, párr. 55).

Igualmente, es importante considerar lo expresado por la Corte en las sentencias de "Indemnización Compensatoria" en los casos contra Honduras (Casos Velásquez y Godínez) donde señala que la "justa indemnización" del artículo 63.1 de la Convención debe entenderse como compensatoria y no sancionatoria. Desde estos primeros casos contenciosos la Corte precisó que si algunos tribunales internos (como los angloamericanos), fijan indemnizaciones cuyos valores tienen propósitos ejemplarizantes o disuasivos, este principio no es aplicable en el Sistema Interamericano (Corte IDH, Serie C, No. 39, párr. 43 y 44).

\section{Hechos principales del Caso de la Corte Suprema de Justicia (Quintana Coello y Otros) vs. Ecuador}

El Caso que se analiza en el presente artículo, tiene que ver con la remoción arbitraria e ilegal de 27 magistrados de la Corte Suprema de Justicia del Ecuador efectuada por el Congreso Nacional en el año 2004. Este acto de irresponsabilidad política violó las garantías mínimas del debido proceso. Los ex magistrados no fueron escuchados ni tuvieron oportunidad de defenderse.

Esta remoción arbitraria de las víctimas lesionó sus bienes patrimoniales, que provocó que dejaran de percibir sus legítimos ingresos: salarios y demás beneficios laborales y de seguridad social. Además, con la legítima expectativa de continuar en sus cargos, y consecuentemente percibir normalmente sus remuneraciones, con las que pudieron haber adquirido compromisos de índole económica, que a raíz de lo acontecido ya no podrían cubrir. Como prueba de esta situación la Corte consideró las declaraciones de varios ex magistrados que dieron testimonio de "las circunstancias calamitosas y 
difíciles que han tenido que afrontar como consecuencia del desempleo arbitrario al que se vieron avocados". ${ }^{1}$

La Corte IDH consideró que, debido al cambio de la Constitución del país, efectuado en el año 2008 (20 de octubre) no es posible afirmar que los ex magistrados que hacían parte de la Corte Suprema de Justicia hubiesen seguido en sus cargos si no hubieran sido destituidos. Por ello se limitó hasta esa fecha el daño material. Además, la Corte Suprema fue eliminada y cambiada por la Corte Nacional de Justicia con 21 jueces (elegidos mediante sorteo entre quienes conformaban a la fecha la Corte Suprema).

Lo expresado es un punto importante que hay que considerar, porque en este contexto ya no era posible reintegrar a los "ex magistrados de la Suprema", como pide la sentencia, y no resulta lógico imponer al Estado ecuatoriano el pago de USD \$60.000,00 (DÓLARES DE LOS ESTADOS UNIDOS DE AMÉRICA) a cada uno de los exmagistrados por no ser posible su reintegro.

Luego de los cálculos respectivos y del análisis de las liquidaciones del año 2005 al 2008 (tiempo menor a los cuatro años) la Corte consideró como justa indemnización por daño material a cada uno de los 27 ex magistrados una cifra promedio que pasa los USD $\$ 400.000,00$ (DÓLARES DE LOS ESTADOS UNIDOS DE AMÉRICA) (no se entrará en el detalle de los valores).

Se debe destacar el caso de ex magistrados que desempeñaron otros cargos públicos después de haber sido cesados de la Corte Suprema de Justicia. Por lo que el impacto del perjuicio calculado ya no llegaba a tales límites y se iba a proceder a un descuento de los valores diferenciales. Para lo cual la Corte pidió al Estado que aportara pruebas sobre esta cuestión y otras, e incluso otorgó un plazo para que el Estado remitiera esta información, cosa que no ocurrió.

1 Testimoniaron, entre otros, los Dres. Arturo Donoso, Miguel Moreno, Bermeo Casti1lo, Brito Mieles, Ramírez Álvarez, Riofrío Corral y Salinas Montaño. En mi criterio, esta actitud (de lamentación) afecta la dignidad de quien ostentó un alto cargo público. 
Frente a la negligencia del Estado en entregar la documentación necesaria, a criterio personal, la Corte debió haber actuado de oficio y pedir pruebas para mejor proveer. Lo que hubiera permitido calcular con mayor certidumbre los montos indemnizatorios al tiempo de fortalecer la convicción del juzgador.

Esta situación la considero lamentable, porque al menos hubo cuatro exmagistrados que volvieron a trabajar en la Corte Suprema, once meses después de que fueron cesados (Dres. Vicente Troya Jaramillo, juez; Jaime Velasco Dávila, juez; Teodoro Coello Vásquez, juez; Arturo Donoso Castellón, asesor). Lo lamentable es que quienes ejercieron un cargo de alta investidura guardaran silencio con el fin de cobrar las indemnizaciones; sobra decir que tal conducta, además de no ser ética, es vergonzosa.

A la mencionada indemnización por daño material hay que agregar, como fue dicho, los USD \$60.000,00 (DÓLARES DE LOS EE.UU.) para cada uno de los ex magistrados "por no ser posible la reintegración a sus cargos". Y como daño inmaterial o moral se concedió la suma de USD \$5.000,00 (DÓLARES DE LOS EE.UU.) a cada uno. En este punto vale señalar que, no pocas veces, los representantes legales de la parte lesionada proponen exigencias desmesuradas. Para este caso fue demandada la cantidad de USD \$500.000,00 (DÓLARES DE LOS EE.UU.) para cada uno como daño moral. Pretensión absurda.

Por último, la Corte fijó los valores por las costas y los gastos ocasionados por la defensa judicial, a más de otros ítems. La suma total de esta indemnización pecuniaria pasa los USD \$12'500.000,00 (DÓLARES DE LOS EE.UU.)

A dicho monto indemnizatorio se deberá sumar el costo de otra demanda similar, por la destitución de 8 vocales del Tribunal Constitucional (ocasionado en la misma fecha y con igual arbitrariedad), el Caso Camba Campos y Otros vs. Ecuador. En este caso, la Corte reconoce un total aproximado de USD \$2'400.000,00 (DÓLARES DE LOS EE.UU.): a cada uno de los siete vocales se indemniza con un promedio cercano a los USD \$250.000,00 (DÓLARES DE LOS EE.UU.) y de USD \$10.000,00 (DÓLARES DE LOS 
EE.UU.) al octavo vocal y a otros suplentes; se agregan costas y gastos por USD $\$ 7.000,00$. También se indemniza a cada vocal con USD \$60.000,00 (DÓLARES DE LOS EE.UU) por la imposibilidad de volver a los cargos.

Es decir, Ecuador pagó alrededor de quince millones de dólares en estos dos casos. El presente análisis se centrará en el caso de los ex magistrados de justicia por ser más emblemático que el Caso Camba Campos y Otros del Tribunal Constitucional ecuatoriano.

\section{Naturaleza de las Indemnizaciones}

Una de las finalidades que tienen las reparaciones en los casos de violación a los derechos humanos, es que los Estados responsables tomen conciencia de los atropellos cometidos y que tales situaciones no vuelvan a repetirse posteriormente. Por ello, es tan importante que los Estados investiguen, juzguen y sancionen a los responsables de la violación de derechos, porque sólo así se combate la impunidad.

En este punto vale señalar que lo dicho no puede conseguirse a través de las indemnizaciones. Según la doctrina y práctica de nuestros países, con excepción de los países anglosajones, los montos indemnizatorios tienen un carácter de reparación compensatoria para las víctimas y sus familiares. En cambio, en los países anglosajones las indemnizaciones constituyen una forma de sanción para quien ha violado derechos. En este sentido se ha desenvuelto la jurisprudencia de la Corte Interamericana. Cuando dispone indemnizaciones estas no tienen un carácter sancionador para el Estado responsable de vulnerar derechos. Como se dijo, se trata de reparaciones compensatorias e igualmente se reitera que, con esta misma orientación, las sentencias de la Corte Interamericana suelen señalar que las indemnizaciones no enriquecen ni empobrecen a las víctimas y a sus familiares; regla establecida desde los primeros casos contenciosos.

Frente a lo expresado, a criterio personal, la sentencia contiene un matiz sancionador. Se busca que el Estado ecuatoriano corrija las actuaciones arbitrarias e ilegales y antidemocráticas que afectan a la 
Administración de Justicia, especialmente en todo cuanto se refiere a la independencia e imparcialidad de los jueces.

También mencionar que el autor comparte plenamente los razonamientos que sobre este punto desarrolla no sólo esta sentencia sino toda la jurisprudencia del Órgano interamericano. Sin embargo, las malas costumbres políticas de nuestros Estados no pueden ser cambiadas a través de imponer altos montos indemnizatorios que finalmente están lejos de afectar a los actores políticos, responsables de la desinstitucionalización de un país. Cuestión lamentable que hoy constata el Ecuador respecto de la década en que el expresidente Correa ejerció un poder autoritario de los valores pagados por el Estado. No obstante que la acción de repetición consta en la propia Constitución de 2008. Y, una de las razones es que al expresidente Correa lo único que le interesó fue blandir esta sentencia en contra de sus adversarios políticos como instrumento de sujeción y amenaza. Ello explica la ambigua conducta del entonces Procurador General en la defensa del Estado, que incumplió su deber.

Por otro lado, siempre he sostenido que, en la mayoría de los casos, las indemnizaciones dictadas por la Corte son meramente simbólicas, ya que es muy difícil tratándose de vulneración a los derechos humanos, resarcir el daño en su totalidad, pensemos en la afectación de la libertad, de la integridad personal o de la vida. En suma, reparar e indemnizar tienen la finalidad de colocar a la víctima de una violación en una posición más o menos similar a la que se encontraba antes de la ocurrencia del hecho ilícito, siempre que esto sea posible.

Insisto que las indemnizaciones son simbólicas porque la vida y la libertad de un ser humano no pueden ser monetariamente valoradas. Se recuerda el caso ecuatoriano de la profesora Benavides Cevallos ejecutada por su ideología (como sucedió con el profesor Caballero Delgado, en Colombia) a cuyos familiares el Estado ecuatoriano entregó como solución amistosa un millón de dólares de indemnización; sin embargo, cuando la Corte revisó el cumplimiento de la sentencia declaró incumplida la misma. En otras palabras, no sirvió al Ecuador dar una generosa indemnización y no cumplir con 
lo principal que es investigar, juzgar y sancionar a los responsables de tales delitos (Corte IDH, Serie C, No. 31, párr. 43, 46, 47, 50).

En el caso colombiano de Caballero Delgado, similar al caso ecuatoriano, la Corte IDH consideró una indemnización aproximada de USD \$150.000,00 (DÓLARES DE LOS EE.UU.). Ciertamente simbólica. Su cadáver no fue encontrado. En el Caso Neira Alegría y otros vs. Perú (tres víctimas muertas y desaparecidos sus cadáveres en los hechos sucedidos en el Penal "El Frontón" frente a Lima, en 1986) la reparación indemnizatoria llegó a 154 mil dólares para los familiares de las tres personas (Corte IDH, Serie C, No. 29).

Con base en lo expresado, se puede decir que el elevado monto indemnizatorio otorgado por el Tribunal Interamericano en el caso de los exmagistrados de justicia va más allá de ser simbólico y que sí ha enriquecido a los antiguos jueces. Ya no se trata de una reparación compensatoria, sino que adquiere la forma de una indemnización sancionatoria para el Estado ecuatoriano, que en fin de cuentas serán los estratos medio y bajo de la sociedad los que correrán con esta carga indemnizatoria.

Los miembros de la Corte pasaron por alto que estas indemnizaciones representaban un alto desembolso de dinero público por parte de un Estado que tiene un ingreso fiscal reducido. Pagar una indemnización mayor a doce millones y medio de dólares (solo en este caso) significa invertir menos en salud y educación. ${ }^{2}$

Además, frente al monto de esta indemnización me ha preocupado que en los doce años que permanecí como juez en esta Corte, las indemnizaciones concedidas por muerte de la víctima o víctimas se hayan caracterizado por oscilar en un promedio de $100 \mathrm{mil} \mathrm{a}$ 300 mil dólares. Y se tratan de muertes ocasionadas por los agentes del Estado con violencia y tortura, muchas veces con desaparición del cadáver de la víctima y también con desapariciones forzadas.

2 Recuerdo haber escuchado voces de disgusto, reclamando un equilibrio entre los “derechos económicos" de los exmagistrados versus el interés de la sociedad. 
Están, por ejemplo, los casos de la "Panel Blanca" (Caso Paniagua Morales y Otros) (Corte IDH, Serie C, No. 37); Caso de los "Niños de la Calle" (Caso Villagrán Morales y Otros). En estos como en otros casos el monto indemnizatorio se reparte entre los familiares de las víctimas (Corte IDH, Serie C, No. 77).

¿Cómo explicar esta gran diferencia de montos indemnizatorios? Todos conocemos el procedimiento que utiliza la Corte para establecer, en cada caso, el daño material (lucro cesante y daño emergente). El método se basa en el salario que dejó de percibir la víctima, mientras para unos -que son la mayoría- se les reconoce el salario mínimo vital que existe en el respectivo Estado, para otros -los menos- tienen elevados salarios (salarios dorados, se podría decir). Para los primeros, la indemnización es simbólica, para los segundos significa un enriquecimiento.

\section{El reto de buscar un método que concilie la Desigualdad Social}

En el contexto analizado, consideremos que el problema indemnizatorio debe ser resuelto aplicando reglas diferentes a las que se han venido utilizando: reglas de equidad, de no discriminación y otros factores más específicos sincronizados con la realidad socio-económica.

Para determinados casos, como el de los exmagistrados del Ecuador, debe existir un límite máximo para establecer el daño material. Por el contrario, para aquellas víctimas que están en situación de marginalidad social, desprovistos de educación y de una fuente de trabajo, se debe mejorar el monto indemnizatorio. En el sentido de no regirse solamente por el salario mínimo que hay en un Estado, cuestión que va a incidir en el monto final porque se va a considerar que esa persona carente de educación quedaría toda su vida (si no hubiera muerto) esclavizado a ese mínimo vital.

Resulta obvio que, en tales circunstancias, si se mantiene la forma actual de calcular las indemnizaciones, estos estratos sociales nunca 
alcanzarán un monto indemnizatorio significativo y digno como una forma de reparación. Si se analiza detenidamente los perjuicios que fueron ocasionados a los exmagistrados de Justicia del Ecuador al ser despojados de su cargo por el Estado, en clara violación de sus derechos, se tendría la siguiente visión.

En primer lugar, al tener el título profesional de abogados, con práctica y prestigio en el medio jurídico, es difícil aceptar que queden en la desocupación. Obviamente ya no percibirán el sueldo y las canonjías que tenían en la Corte Suprema de Justicia, pero nunca estarán en la situación de la mayoría de ciudadanos que pugnan día a día por un trabajo mejor remunerado.

Ciertamente que se trastornó el proyecto de vida, como puede ser disponer de una casa propia o comprar un departamento en la playa porque el salario de un ex juez le permitía disfrutar de tal situación, o de adquirir un vehículo nuevo, etc. Sin embargo, también es cierto que los jueces destituidos no estaban impedidos de trabajar como abogados.

Si bien no desconozco que un proyecto de vida es una legítima expectativa, sin embargo, esta situación mirada desde una perspectiva social, solidaria, justa, no es compatible con la realidad que vive la mayoría. De aquí viene mi afirmación de que dicha indemnización es altamente discriminatoria: a la sociedad se la mide en parámetros desiguales. Situación que no debe darse, menos en el campo de los derechos humanos.

Y aquí podemos invocar a los derechos económicos, sociales, culturales y ambientales, que están negados a quienes sufren pobreza e indigencia. ¿Cómo alcanzar un proyecto de vida que dignifique a la persona? Tal cosa será posible sólo para un estrato social pequeño, como el de los ex magistrados de la Corte Suprema del Ecuador o de cualquier otro país. Mucho se podría reflexionar sobre la inequidad y sobre la realidad social que encierran estos casos.

Otro punto a considerar, para evitar que la indemnización sea discriminatoria de unos estratos sociales frente a otros, sería el elevar el monto del daño moral con base en determinados factores familiares 
y sociales que se presentan en cada caso específico y que existen en un país los cuales deben ser establecidos de manera objetiva. Por otro lado, es natural que el grado de afectación o de perjuicio moral que sufre una familia se agrava cuando se dan casos de víctimas que han perdido la vida por desapariciones forzadas o por ejecuciones extrajudiciales, peor cuando existe la desaparición de los restos mortales.

\section{Conclusiones}

Se debe señalar que este punto no ha estado ausente en muchas de las sentencias de reparación que ha dado la Corte Interamericana. Mejorar la reparación por daño moral ha permitido a la Corte dar alguna significación al monto indemnizatorio, cuyo daño material suele ser ínfimo al estar fundado en el salario mínimo que tiene un país, peor si tiene una moneda devaluada con relación al dólar (moneda que utiliza la Corte para fijar las indemnizaciones).

En este sentido, de elevar el monto del daño moral (aunque sea moderadamente), se debe recordar los casos de Guatemala: la "Panel Blanca" (Caso Paniagua Morales y Otros), los "Niños de la Calle" (Caso Villagrán Morales y Otros) ambos con sentencia de reparaciones en 2001. También el Caso Bámaca Velásquez, sentenciado en 2002.

Por último, reitero que al tomar el Caso de los ex Magistrados de la Corte Suprema del Ecuador la intención del autor, ha sido de contribuir con un pequeño aporte en las reflexiones que continuarán haciéndose en el seno de la Corte IDH. Además, señalar paladinamente que me encuentro de acuerdo con la "reparación integral" que dispone el Tribunal en sus sentencias ya que garantiza la investigación de los hechos, restitución de derechos, bienes y libertades, la rehabilitación física, psicológica o social, entre otros aspectos. 


\section{Referencias Bibliográficas}

Convención Americana sobre Derechos Humanos o Pacto de San José. (1969).

\section{Jurisprudencia Internacional}

Corte Interamericana de Derechos Humanos. Caso Velázquez Rodríguez vs. Honduras. Reparaciones y Costas. Sentencia de 21 de julio de 1989. Serie C No. 7

Corte Interamericana de Derechos Humanos Caso Neira Alegría y Otros. Reparaciones y Costas. Sentencia de 19 de septiembre de 1996, Serie C, No. 29.

Corte Interamericana de Derechos Humanos. Caso Caballero Delgado y Santana vs. Colombia. Reparaciones y costas. Sentencia de 29 de enero de 1997. Serie C, No. 31.

Corte Interamericana de Derechos Humanos. Caso Garrido y Baigorria vs. Argentina. Reparaciones y Costas. Sentencia de 27 de agosto de 1998. Serie C, No. 39

Corte Interamericana de Derechos Humanos. Caso Castillo Páez vs. Perú. Reparaciones y Costas. Sentencia de 27 de noviembre de 1998. Serie C, No. 43.

Corte Interamericana de Derechos Humanos. Caso de la "Panel Blanca" (Paniagua Morales y otros) vs. Guatemala. Reparaciones y Costas. Sentencia de 25 de mayo de 2001. Serie C, No. 76.

Corte Interamericana de Derechos Humanos. Caso de los "Niños de la Calle” (Villagrán Morales y otros) vs. Guatemala. Reparaciones y Costas. Sentencia de 26 de mayo de 2001. Serie C, No. 77.

Corte Interamericana de Derechos Humanos. Caso de la Corte Suprema de Justicia (Quintana Coello y otros) vs Ecuador. Excepción Preliminar, Fondo, Reparaciones y Costas. Sentencia de 23 de agosto de 2013. Serie C, No. 266. 